revealed prenatally. Girl was born on 27.05.2018. At birth the diagnosis of $\mathrm{BE}$ and multiple dysembryogenic stigmas was made. The girl was transferred to the $\mathrm{NMRCCH}$ in an urgent order at first 24 hours of life.

On presentation: BE, total epispadia, divergent labia minora and majora, pubic bones diastasis (up to $4.6 \mathrm{~cm}$ ). There was a defect on anterior abdominal wall wherethrough bladder mucous membrane was prolapsing. Anus was normal. External sex organs were abnormal, child gender couldn't be identified adequately. The uterus was prolapsing due to anxiety at first 24 hours of life. Acrocephaly, frontal bone persistence, fingers and toes complete syndactyly, uranostaphyloschisis and choanal atresia came under notice.

Results We have performed primary repair of bladder with local flaps on $5^{\text {th }}$ day. Later we performed rehabilitation measures.

Due to molecular genetic testing we revealed heterozygous mutation c.755C $>G$ (p.Ser252Trp) in FGFR2 gene (Apert syndrome, autosomal dominant disorder).

Long-term outcomes were estimated at six months age. The child is tube fed, puts on weight and develops. Urinary system infections took place twice due to vesicoureteral reflux. Note that bladder voiding and storage functions are adequate. Bladder volume is $60 \mathrm{ml}$ and the interval between urinations is about 1 hour. Following step is to perform neurosurgical treatment. Orthopedic surgery should be performed in older age.

Conclusion Bladder exstrophy treatment in newborns even comorbid with other MCAs is optimal and shall be carried out in referral centres. The choice and validation of surgery method for BE treatment demand personalized approach. Multidisciplinary approach in management of these patients is important in the presence of other MCAs.

\section{GP77 OCULOCUTANEOUS ALBINISM IN A NEONATE}

${ }^{1}$ Jayasree Kutty*, ${ }^{1}$ Rukhsana Nazli, ${ }^{2}$ Nicholas Cotton, ${ }^{3}$ Rosie Brennan. ${ }^{1}$ Department of Paediatrics, SouthWest Acute Hospital, Enniskillen, UK; ${ }^{2}$ Department of Ophthalmology, Royal Victoria Hospital, Belfast, UK; ${ }^{3}$ Department of Ophthalmology, Altnagelvin Hospital, Derry, UK

\subsection{6/archdischild-2019-epa.143}

Background Oculocutaneous albinism (OCA) is a genetically heterogeneous group of disorders affecting melanin biosynthesis. It is always an autosomal recessive inheritance and is characterized by decreased or absent pigmentation of hair, skin, iris and retina. Clinical presentation is typically of an infant who does not appear to see at the expected 6-8 week corrected age, often with nystagmus and pale pigmentation. Clinical findings demonstrate grossly obvious iris attenuation and iris transillumination, refractory errors and photophobia. Investigations include genetic testing, Optical Coherence Tomography (OCT) to identify foveal hypoplasia and electrophysiology to establish any excessive crossing of optic nerve fibres at the optic chiasma.

Method A Caucasian female, born to non-consanguineous parents was referred to Paediatric services at one week of age with concerns regarding her pale hair, eyelashes and diffuse pink reflex from both eyes. On examination she had marked iris transillumination without nystagmus and significant hypermetropic astigmatism for which glasses were prescribed. Her father had iris transillumination and nystagmus but met the visual standards to drive. By eight weeks, the infant had developed nystagmus and was showing some visual awareness. Developmental examination was age appropriate.

Results At initial presentation the expectation of delayed visual maturation was explained to the parents with reassurance that once vision has matured, OCA is a stable condition. Advice was given regarding protection from solar damage as well as the importance of regular skins checks in view of the possible increased risk of skin cancers. The family history and the phenotypical variability between OCA subtypes prompted gene testing to arrive at a molecular diagnosis.

Conclusion The case highlights the importance of early identification so families are aware of the natural history of OCA as well as the need to protect skin from UV damage. Carrier detection and personalised genetic counselling are possible once the disease causing mutations in the family are identified.

\section{GP78 DILATED CARDIOMYOPATHY WITH ROSS III HEART FAILURE INDUCED BY SEVERE IRON DEFICIENCY ANAEMIA POST LONG TERM COW MILK EXCESS}

\footnotetext{
${ }^{1,2}$ Gabriela Doros, ${ }^{1,2}$ Andrada Mara Ardelean*, ${ }^{1,2}$ Anca Popoiu, ${ }^{1,2}$ Cristina Olariu

${ }^{1,2}$ Ramona Stroescu, ${ }^{1,2}$ Mihai Gafencu. 'Victro Babes University of Medicine and Pharmacy, Timisoara, Romania; ${ }^{2}$ IIIrd Pediatric Clinic Emergency Hospital for Children Louis Turcanu, Timisoara, Romania
}

\subsection{6/archdischild-2019-epa.144}

Aim To present a 1 year and 6 months old girl and $8.2 \mathrm{~kg}$, admitted in the Emergency Department for extremely pale skin, loss of appetite, intense fatigue, muscular hypotonia, tachycardia, polypnea, grade II systolic murmur, hepatomegaly and Ross III heart failure. From the age of 7 months she started to select the food and finally ate only 1 liter/day cow milk. One day before admittance she was not able to wake up from her bed.

Material and Methods The patient performed lab investigations, cardiopulmonary $\times$ ray, cardiac examination and hematology exploration.

Results Cardiomegaly with increased vascular markings was found on $\times$ Ray. ECG revealed tachycardia $148 \mathrm{~b} / \mathrm{min}$, alternating with bradycardia, $48 \mathrm{~b} / \mathrm{min}$, right atrial dilatation, left ventricle hypertrophy and prolonged QTc 0.45 sec. Echocardiography showed dilated cardiomyopathy, tele diastolic diameter $4.02 \mathrm{~cm}$, EF 0.56 , SF 29\%, grade III mitral regurgitation, grade I aortic regurgitation, minimal pericardial fluid and slight pulmonary hypertension. Cardiac biomarkers as NT pro-BNP was very high, $8817 \mathrm{pg} / \mathrm{mL}$, with elevated CK MB $2.51 \mathrm{ng} / \mathrm{mL}$ and normal Troponin T. Serology for Parvovirus B19 IgM and Coxakie was negative, excluding the viral infection as etiology for dylated cardiomyopthy. Severe anemia with $1.9 \mathrm{~g} / \mathrm{dl} \mathrm{Hb}$ was detected, that imposed rapid blood transfusion. The Iron level, ferritin was $0.1 \mathrm{ng} / \mathrm{ml}$, extremely low. Seriated blood transfusions were necessary until $\mathrm{Hb}$ achieved $10 \mathrm{mg} / \mathrm{dl}$. Concomitant heart failure treatment was started with Furosemide, Spironolactone, Captopril and low dose of Dobutamine. Iron correction was done with oral products. Folic Acid and Vit C was added in treatment. The evolution was slowly good; gradually normal diet was introduced with meat, eggs, vegetables and fruits.

Conclussions Anemia is cited in the literature to induce dylated cardiomyopathy. Our patient had the most decreased reported value of $\mathrm{Hb}$ and Iron, due to long duration of exclussive cow milk daily alimentation. This situation 